\title{
ANALISA PERBANDINGAN CURAH HUJAN BERDASARKAN DATA CITRA NOAA AVHRR DENGAN DATA CURAH HUJAN DI LAPANGAN
}

\author{
Muammar Muzayyin Ramadlon, Teguh Hariyanto \\ Program Studi Teknik Geomatika FTSP-ITS, Kampus ITS Sukolilo, Surabaya, 60111 \\ Email : za_anfavi@rocketmail.com,tgh_hary@yahoo.com
}

\begin{abstract}
Abstrak
Peraturan Pemerintah No. 26 tahun 2008 menjelaskan bahwa Pulau Jawa merupakan salah satu kawasan strategis nasional (KSN) sebagai kawasan pertumbuhan ekonomi yang meliputi Provinsi Jawa Timur, Provinsi Jawa Tengah, Provinsi DI Yogyakarta, Provinsi Jawa Barat, Provinsi DKI Jakarta, dan Provinsi Banten. Bidang pertanian merupakan salah satu sektor andalan kawasan Pulau Jawa. Salah satu visi misi wilayah Pulau Jawa yaitu peningkatan lahan produktif untuk peningkatan produktivitas pertanian. Salah satu faktor penunjang yang dibutuhkan dalam peningkatan produktivitas pertanian adalah pengetahuan tentang distribusi curah hujan.

Penelitian ini akan membahas dan menganalisa tentang tingkat curah hujan di Pulau Jawa menggunakan metode penginderaan jauh dari data citra satelit NOAA AVHRR. Hasil pengolahan dari citra NOAA AVHRR tersebut kemudian dianalisa dengan cara membandingkan data tersebut dengan data curah hujan hasil pengukuran in situ yang didapat dari Badan Meteorologi Klimatologi dan Geofisika (BMKG) pusat. Algoritma yang digunakan pada penelitian ini menggunakan algoritma suhu kecerahan yang dirumuskan oleh Parwati (2009).

Hasil yang diperoleh dari penelitian ini menunjukkan bahwa nilai korelasi $\left(R^{2}\right)$ antara data lapangan dengan data curah hujan NOAA AVHRR-19 pada bulan Juli sebebesar 0,430, bulan Agustus sebesar 0,499, bulan November sebesar 0,464, dan bulan Desember sebesar 0,440. Kemudian nilai intensitas curah hujan yang diperoleh dari citra NOAA AVHRR-19 berupa estimasi minimal curah hujan pada bulan November-Desember sebesar 1,806 $\mathrm{mm} /$ jam dan estimasi maksimal sebesar 9,304 mm/jam. sedangkan pada pada bulan Juli-Agustus, nilai estimasi minimal curah hujan sebesar 0,0 mm/jam dan estimasi maksimal sebesar 5,047 mm/jam.
\end{abstract}

Kata Kunci : curah hujan, penginderaan jauh, citra satelit NOAA AVHRR-19, algoritma, korelasi.

\section{PENDAHULUAN}

\section{Latar Belakang}

Pulau jawa dalam Peraturan Pemerintah No. 26 tahun 2008 merupakan salah satu kawasan strategis nasional (KSN) sebagai kawasan pertumbuhan ekonomi yang meliputi Provinsi Jawa Timur, Provinsi Jawa Tengah, Provinsi DI Yogyakarta, Provinsi Jawa Barat, Provinsi DKI Jakarta, dan Provinsi Banten. Bidang pertanian merupakan salah satu sektor andalan kawasan Pulau Jawa. Salah satu visi misi wilayah Pulau Jawa yaitu peningkatan lahan produktif untuk peningkatan produktivitas pertanian. Salah satu faktor penunjang yang dibutuhkan dalam peningkatan produktivitas pertanian adalah pengetahuan tentang distribusi curah hujan. Selain itu, dengan pengetahuan tersebut maka dapat diketahui daerah mana saja yang rawan terkena banjir akibat ekstrimnya curah hujan yang terjadi (Balitklimat, 2007). Oleh karena itu, dibutuhkan suatu metode yang dapat menyajikan kondisi curah hujan secara tepat.

Curah hujan merupakan salah satu unsur iklim dan hidrologis yang sangat penting. Curah hujan yang cukup menjamin tersedianya kebutuhan air bagi manusia, hewan, dan tanaman. Pada kondisi ekstrim, curah hujan dapat pula menyebabkan terjadinya banjir atau kekeringan. Curah hujan diperlukan dalam pendugaan ketersediaan air bagi tanaman, penentuan batas antara musim hujan dan musim kemarau, serta dalam pengendalian/antisipasi banjir ataupun kekeringan (Prasasti, 2000). 
Dengan semakin berkembangnya teknologi penginderaan jauh, Pemantauan curah hujan pun dapat dilakukan dengan teknologi ini yaitu dengan menggunakan data citra satelit meteorologi (Aljabaro, 2007). Dengan menggunakan teknologi ini, dimungkinkan untuk memantau curah hujan di wilayah wilayah yang sulit dijangkau dengan menggunakan peralatan konvensional. Salah satu citra penginderaan jauh yang dapat digunakan untuk memantau curah hujan, khususnya di wilayah tropis seperti Indonesia, yaitu citra National Oceanic Atmospheric Advanced Very High Resolution Radiometer (NOAA AVHRR) yang merupakan satelit pemantau cuaca dengan kelebihan memiliki 6 band, salah satu kegunaan dari band $3 b$ yaitu dapat menghitung nilai curah hujan.

Penelitian ini membahas dan menganalisa tentang penggunaan citra satelit NOAA AVHRR sebagai salah satu metode pemantauan curah hujan. Hasil yang didapatkan nantinya akan dibandingkan dengan data curah hujan hasil pengukuran secara in situ dari Badan Meteorologi, Klimatologi dan Geofisika (BMKG) Pusat. Hasil akhir dari penelitian ini berupa data nilai curah hujan dari citra NOAA-AVHRR 19 yang selanjutnya dibuat menjadi sebuah peta curah hujan Pulau Jawa tahun 2012 pada bulan Juli, Agustus, November, dan Desember.

\section{METODOLOGI PENELITIAN}

\section{Lokasi Penelitian}

Lokasi penelitian ini mengambil daerah studi di wilayah Pulau Jawa, Letak geografis Pulau Jawa terletak pada 105004'52"- 116017'21" BT dan 5029'05" - 8047'26" LS. Secara umum Pulau Jawa dibagi menjadi empat propinsi, yaitu Jawa Timur, Jawa Tengah, Jawa Barat, dan Banten serta dua wilayah khusus yaitu Daerah Istimewa Yogyakarta dan Daerah Khusus Ibukota Jakarta.

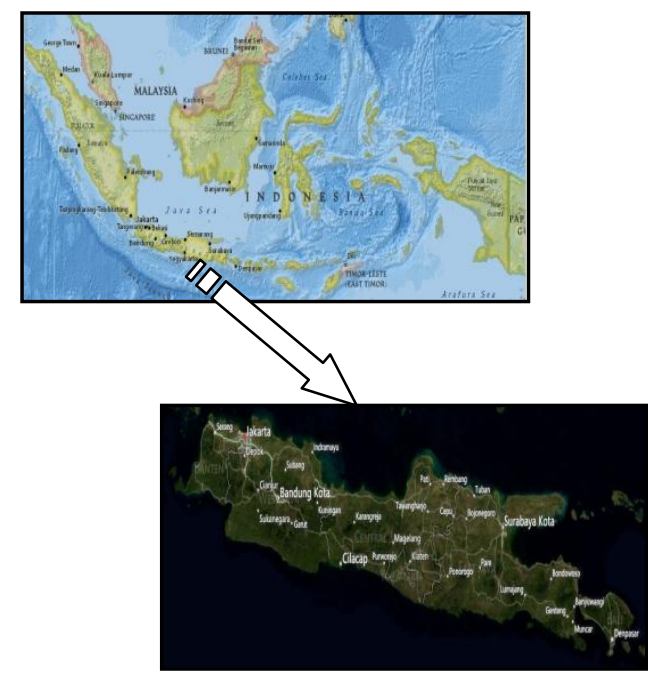

Gambar 1. Lokasi penelitian di Pulau Jawa (sumberhttp://www.arcgis.com/home/webmap/vi ewer.html?useExisting=1)

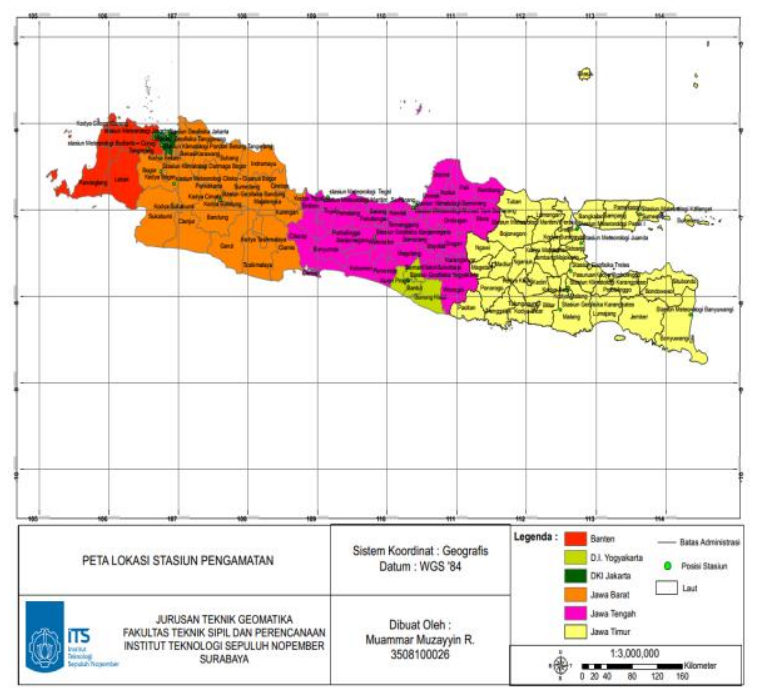

Gambar 2. Stasiun pengamatan BMKG di Pulau Jawa

\section{Data Dan Peralatan}

- Data

Data yang digunakan dalam penelitian ini adalah:

Data NOAA-19 AVHRR tahun 2012.

Data curah hujan Pulau Jawa dari BMKG tahun 2012.

\section{- Peralatan}

Peralatan yang digunakan dalam penelitian adalah berupa perangkat keras yaitu laptop untuk prosessing data dan perangkat lunak berupa software pengolah data spasial. 
Diagram Alir Pengolahan Data

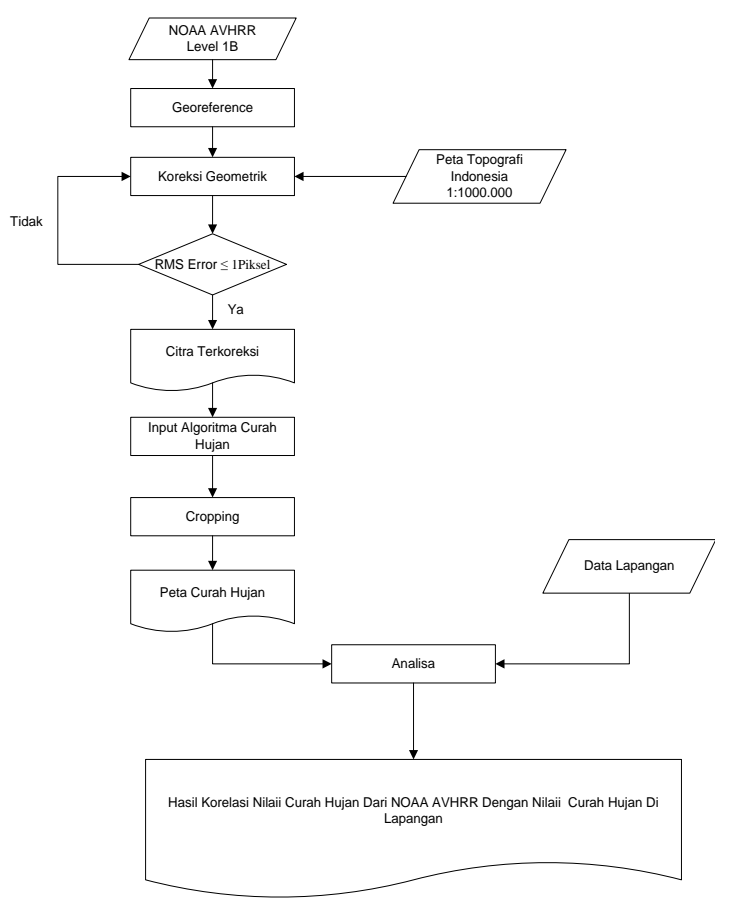

Gambar 3. Diagram Tahap Pengolahan Data

Penjelasan untuk diagram alir diatas adalah:

Pada tahap ini dilakukan analisis terhadap kesalahan geometrik terjadi pada citra dan dilakukan analisis terhadap data-data yang diperoleh yaitu curah hujan hasil estimasi dari citra NOAA-AVHRR. Dari hasil pengolahan citra NOAA-AVHRR dan curah hujan lapangan didapatkan distribusi curah hujan sehingga dapat digunakan untuk mengamati curah hujan pada daerah penelitian. Analisa citra NOAA$A V H R R$ dengan data curah hujan lapangan yang memiliki tanggal perekaman yang sama dapat dibandingkan antara keduanya, sehingga didapatkan analisa perbandingan curah hujan yang berasal dari citra NOAA-AVHRR dengan data curah hujan lapangan serta nilai korelasi tiap titik stasiun pengamatan curah hujan yang berada di pulau Jawa.

\section{Algoritma Curah Hujan}

Nilai curah hujan dapat ditentukan dengan telebih dahulu mencari nilai suhu kecerahan awan (TB) dari data numeric citra (Parwati, 2009)

1. Menentukan Suhu Blackbody Efektif $\left(\mathrm{T}_{\mathrm{BB}_{\mathrm{B}}}\right)$
$\mathrm{T}_{\mathrm{BB}}^{*}=\mathrm{A}+\mathrm{BT}_{\mathrm{BB}}$

2. Menentukan Nilai Radiansi Blackbody $\left(\mathrm{N}_{\mathrm{BB}}\right)$

$\mathrm{N}_{\mathrm{BB}}=\frac{\mathrm{C}_{1} \mathrm{~V}_{\mathrm{C}}^{3}}{\mathrm{e}^{\frac{\mathrm{C}_{2} \mathrm{~V}_{\mathrm{C}}}{\mathrm{T} * \mathrm{BB}}-1}}$

3. Menentukan Nilai Gain(G) dan Intercept(I)

$\mathrm{G}=\frac{N_{B B}-N_{S}}{C_{b b}-C_{s}}$

$\mathrm{I}=N_{s}-G C_{s}$

4. Menentukan Nilai Pixel MEnjadi Nilai Radiansi

$\mathrm{Ni}=G_{i} X_{i}+I_{i}$

5. Menentukan Nilai $\mathrm{T}_{\mathrm{bb}}$

$\mathrm{T}_{\mathrm{bb}}=\frac{C_{2} V_{2}}{\operatorname{Ln}\left[1+\frac{C_{1} V_{c}^{3}}{N i}\right]}$

6. Menentukan Nilai TB

$\mathrm{TB}=\frac{T_{b b}-A}{B}$

Keterangan :

$\mathrm{T}^{*}{ }_{\mathrm{BB}} \quad=$ Suhu Blackbody Efektif( $\left.\mathrm{k}\right)$

$\mathrm{T}_{\mathrm{BB}} \quad=$ Suhu Apparet Blackbody (dari telemetri data) ( $k$ )

$\mathrm{N}_{\mathrm{BB}} \quad=$ Radiansi Blackbody $\left(\mathrm{Wm}^{-2} \mathrm{k}^{-4}\right)$

$\mathrm{C}_{1}=$ konstanta radiansi $=1,1910427 \times 10^{-}$ ${ }^{5} \mathrm{~mW} /\left(\mathrm{m}^{2}-\mathrm{sr}-\mathrm{cm}^{-4}\right)$

$\mathrm{C}_{2} \quad=$ konstanta radiansi $=1,4387752 \mathrm{~cm}-\mathrm{K}$

$\mathrm{Vc}=$ bilangan gelombang pusat (centroid wavenumber)

$\mathrm{G} \quad=$ koefisien Gain $\left(\mathrm{Wm}^{-2} \mathrm{k}^{-5}\right)$

NS = Radiansi Angkasa(k)

$\mathrm{C}_{\mathrm{bb}} \quad=$ Count BlackbodyRata-Rata (dari telemetri data) (k)

Cs = CountAngkasa Rata-Rata (dari telemetri data) (k)

$\mathrm{T}_{\mathrm{bb}} \quad$ = Suhu Blackbody Rata-Rata(k)

$\mathrm{I}=$ koefisien Intercept $(\mathrm{k})$

$\mathrm{X} \quad=$ nilai keabuan piksel

I = indeks i menunjukkan bandinframerah

Tabel 1. Koefisien Radiansi Saluran Infra Merah Termal dan Koefisien Radiansi Angkasa NOAA-19 (sumber : Parwati,2009). 
Estimasi curah hujan dengan menggunakan perhitungan teknik model awan. Nilai suhu

\begin{tabular}{ll}
\hline Sifat Curah Hujan & Intensitas Curah Hujan (mm/jam) \\
\hline Tidak ada hujan & $<1$ \\
Hujan ringan & $1-5$ \\
Hujan normal & $5-10$ \\
Hujan lebat & $10-20$ \\
Hujansangat lebat & $>20$ \\
\hline
\end{tabular}

kecerahan awan dapat mewakili suhu puncak awan(Bendix,J.1997).Adler mengusulkan formula berikut:

$R=74,89-0,266 T_{c}$

Dimana :

$\mathrm{R}$ : Curah hujan ( $\mathrm{mm} / \mathrm{jam})$

$T_{c}$ : Suhu puncak awan/ Suhu kecerahan $\left({ }^{0} \mathrm{~K}\right)$

Tabel 2. Klasifikasi Intensitas Hujan Harian MenurutBMKG(sumber:http://meteo.bmg.go.id/cu acamingguan.jsp)

\section{HASIL DAN PEMBAHASAN}

\begin{tabular}{rr}
\multicolumn{1}{c}{ Tanggal } & RMS error rata-rata(pixel) \\
\hline 01 Juli 2012 & 0,3 \\
02 Juli 2012 & 0,2 \\
09 Juli 2012 & 0,4 \\
21 Juli 2012 & 0,4 \\
27 Juli 2012 & 0,4 \\
28 juli 2012 & 0,4 \\
04 Agustus 2012 & 0,3 \\
05 Agustus 2012 & 0,3 \\
16 Agustus 2012 & 0,4 \\
24 agustus 2012 & 0,3 \\
25 agustus 2012 & 0,6 \\
\hline
\end{tabular}

\section{Koreksi Geometrik Citra}

Hasil koreksi geometrik citra NOAA diperoleh nilai rata-rata RMS error sebesar $<0,6$. Hasil RMS rata-rata citra mempunyai nilai RMS ratarata kurang dari 1 pixel sehing dianggap memenuhi toleransi yang diberikan (Purwadhi, S.H, 2001)
Tabel 3. RMS error Citra NOAA AVHRR bulan kering

\begin{tabular}{|c|c|c|c|c|}
\hline Channel / Band & $\mathrm{V}_{\mathrm{c}}$ & $A$ & $B$ & $\mathrm{~N}_{\mathrm{s}}$ \\
\hline 3B & 267,0 & 1,673 & 0,997 & 0 \\
\hline 4 & 928,9 & 0,539 & 0,998 & $-5,33$ \\
\hline \multirow[t]{2}{*}{5} & 831,9 & 0,360 & 0,998 & 2,22 \\
\hline & Tanggal & \multicolumn{3}{|c|}{$\begin{array}{l}\text { RMS error rata- } \\
\text { rata(pixel) }\end{array}$} \\
\hline \multicolumn{2}{|c|}{01 November 2012} & \multicolumn{3}{|c|}{0,2} \\
\hline \multicolumn{2}{|c|}{08 November 2012} & \multicolumn{3}{|c|}{0,4} \\
\hline \multicolumn{2}{|c|}{10 November 2012} & \multicolumn{3}{|c|}{0,4} \\
\hline \multicolumn{2}{|c|}{01 Desember 2012} & \multicolumn{3}{|c|}{0,1} \\
\hline \multicolumn{2}{|c|}{08 Desember 2012} & \multicolumn{3}{|c|}{0,2} \\
\hline \multicolumn{2}{|c|}{09 Desember 2012} & \multicolumn{3}{|c|}{0,4} \\
\hline
\end{tabular}

Tabel 4. RMS error Citra NOAA AVHRR bulan basah

\section{Analisa Curah Hujan Citra NOAA AVHRR Dengan Data Lapangan. \\ Dari hasil pengolahan curah hujan estimasi menggunakan citra NOAA-AVHRR didapatkan nilai curah hujan yang beragam pada semua citra sebagai berikut:}


Tabel 5 Tabel Nilai Curah Hujan Rata-Rata Bulanan(mm/jam) NOAA-19 AVHRR Dengan Data Lapangan Tahun 2012.

\begin{tabular}{|c|c|c|c|c|c|c|c|c|c|}
\hline \multirow[t]{3}{*}{ No } & \multirow[t]{2}{*}{ Nama Stasiun } & \multicolumn{4}{|c|}{ Data Lapangan Th. 2012 (mm/Jam) } & \multicolumn{4}{|c|}{ Data NOAA AVHRR Th. 2012 (mm/Jam) } \\
\hline & & Juli & Agustus & Nov & Des & Juli & Agustus & Nov & Des \\
\hline & Jawa Timur & & & & & & & & \\
\hline 1 & Stasiun Klimatologi Karangploso & TAH & 5,7 & 4,2 & 8 & 3,167 & 3,557 & 3,679 & 3,666 \\
\hline 2 & Stasiun Meteorologi Juanda & TAH & $\mathrm{TAH}$ & 1,9 & 5,5 & 3,787 & 3,650 & 2,624 & 4,647 \\
\hline 3 & Stasiun Meterorologi Perak I & 5,6 & $\mathrm{TAH}$ & 1,6 & 6,9 & 1,876 & 1,481 & 2,192 & 5,548 \\
\hline 4 & $\begin{array}{l}\text { Stasiun Meteorologi Maritim/ Perak } \\
\text { II }\end{array}$ & TAH & TAH & 2,7 & 10,2 & 1,552 & 1,107 & 2,375 & 5,666 \\
\hline 5 & Stasiun Meteorologi Banyuwangi & 2 & 0,3 & 2,6 & 5 & 0 & 0 & 3,271 & 5,494 \\
\hline 6 & Stasiun Meteorologi Kalianget & 8,4 & $\mathrm{TAH}$ & 2,1 & 5,4 & 3,594 & 2,718 & 1,807 & 3,308 \\
\hline 7 & Stasiun Geofisika Karangkates & 5,5 & TAH & 6,9 & 10 & 3,915 & 2,931 & 2,433 & 6,118 \\
\hline 8 & Stasiun Geofisika Tretes & 8,5 & TAH & 4,8 & 7 & 4,764 & 5,248 & 3,862 & 3,743 \\
\hline \multirow[t]{2}{*}{9} & $\begin{array}{l}\text { Stasiun Meteorologi Sangkapura } \\
\text { Bawean }\end{array}$ & 2 & 0,03 & 8 & 15 & 0 & 0 & 3,678 & 6,301 \\
\hline & Jawa Tengah & & & & & & & & \\
\hline 1 & Stasiun Meteorologi Tegal & 4,3 & $\mathrm{TAH}$ & 6,8 & 16,5 & 2,886 & 2,191 & 2,128 & 9,418 \\
\hline 2 & Stasiun Meteorologi Cilacap & 5,6 & 0,3 & 24,9 & 9 & 3,470 & 2,147 & 5,023 & 5,163 \\
\hline 3 & Stasiun Geofisika Banjarnegara & 6,2 & 4,9 & 26,9 & 6 & 4,138 & 3,384 & 6,877 & 4,072 \\
\hline 4 & Stasiun Klimatologi Semarang & 1 & TAH & 13 & 14,9 & 1,835 & 1,842 & 6,080 & 8,911 \\
\hline 5 & $\begin{array}{l}\text { Stasiun Meteorologi Ahmad Yani } \\
\text { Semarang }\end{array}$ & 4,5 & 3 & 14 & 11,9 & 1,835 & 1,842 & 6,080 & 8,911 \\
\hline 6 & $\begin{array}{l}\text { Stasiun Maritim Semarang } \\
\text { Jawa Barat }\end{array}$ & 1,3 & TAH & 20 & 15 & 3,388 & 2,536 & 6,775 & 9,304 \\
\hline 1 & Stasiun Meteorologi Citeko,Bogor & 4,62 & 5,6 & 13 & 15,1 & 4,033 & 3,471 & 6,863 & 6,677 \\
\hline 2 & Stasiun Klimatologi Dramaga,Bogor & 5,3 & 5,4 & 20,3 & 13,8 & 3,371 & 2,553 & 8,528 & 4,727 \\
\hline 3 & Stasiun Geofisika Cemara,Bandung & 5,7 & TTU & 19,9 & 22 & 5,111 & 4,679 & 5,151 & 7,540 \\
\hline 4 & $\begin{array}{l}\text { Stasiun Geofisika Lembang,Bandung } \\
\text { DI Yogyakarta }\end{array}$ & 5,53 & TTU & 15,7 & 15,9 & 4,236 & 3,882 & 6,934 & 6,110 \\
\hline 1 & $\begin{array}{l}\text { Stasiun Geofisika Yogyakarta } \\
\text { Banten }\end{array}$ & 7,4 & $\mathrm{TAH}$ & 10,6 & 9,5 & 3,998 & 5,048 & 4,025 & 4,439 \\
\hline 1 & $\begin{array}{l}\text { Stasiun Klimatologi Pondok } \\
\text { Betung,Tanggerang }\end{array}$ & 7,3 & 4,65 & 16 & 16 & 3,214 & 2,124 & 6,304 & 5,435 \\
\hline 2 & Stasiun Geofisika Tanggerang & 5,4 & 2,77 & 3,65 & 6,3 & 3,089 & 2,091 & 4,727 & 5,065 \\
\hline 3 & Stasiun Meteorologi Serang & 5,5 & TTU & 2,82 & 4,13 & 3,358 & 2,757 & 4,882 & 4,747 \\
\hline 4 & $\begin{array}{l}\text { Stasiun Meteorologi Budiarto } \\
\text { Curug,Tanggerang }\end{array}$ & 6,3 & TTU & 13,2 & 10 & 3,269 & 2,433 & 5,271 & 6,166 \\
\hline 5 & $\begin{array}{l}\text { Stasiun Meteorologi Soekarno Hatta } \\
\text { Cengkareng,Tanggerang } \\
\text { DKI Jakarta }\end{array}$ & 5,8 & 0,05 & 3,81 & 8,34 & 3,304 & 2,726 & 5,321 & 5,745 \\
\hline 1 & $\begin{array}{l}\text { Stasiun Maritim Tanjung } \\
\text { Priok,Jakarta Utara }\end{array}$ & 3 & TAH & 15,8 & 9,3 & 0 & 0 & 6,784 & 5,224 \\
\hline 2 & $\begin{array}{l}\text { Stasiun Meteorologi } \\
\text { Kemayoran,Jakarta Pusat }\end{array}$ & 5,4 & TAH & 17,5 & 13 & 3,475 & 1,825 & 2,957 & 5,382 \\
\hline 3 & $\begin{array}{l}\text { Stasiun Meteorologi Halim Perdana } \\
\text { Kusuma,jakarta Timur }\end{array}$ & 6,7 & TAH & 9,97 & 8 & 3,130 & 1,908 & 4,827 & 5,066 \\
\hline
\end{tabular}

Keterangan:

TAH: Tidak Ada Hujan

TTU: Hujan Tidak Terukur 
Hasil penelitian diperoleh intensitas curah hujan estimasi minimal $1,806 \mathrm{~m}$ Minimal $1,806 \mathrm{~m} / \mathrm{jam}$ dan maksimal 9,304 mm/jam pada bulan Nopember-Desember (bulan basah) dan minimal 0,0 mm/jam dan maksimal 5,047 $\mathrm{mm} / \mathrm{jam}$ pada bulan Juli-Agustus (bulan kering). Selanjutnya adalah langkah untuk memvalidasi curah hujan NOAA AVHRR berdasarkan nilai curah hujan di lapangan. dilakukan perbandingan antara data curah hujan NOAA dengan data lapangan (data curah hujan dari BMKG). Perbandingan ini digunakan untuk mengetahui kecocokan antar kedua data tersebut (validasi data). Metode yang digunakan adalah analisa korelasi dengan rumus yang telah dijelaskan pada tinjauan pustaka.

Berdasarkan informasi curah hujan dari posisi stasiun penakar hujan BMKG, pada bulan Nopember didapatkan nilai curah hujan terendah 1,6 mm/jam dan tertinggi 26,9 $\mathrm{mm} / \mathrm{jam}$ dan Pada bulan Desember nilai hujan terendah $5 \mathrm{~mm} / \mathrm{jam}$ dan tertinggi $22 \mathrm{~mm} / \mathrm{jam}$. Sedangkan pada bula Juli didapatkan nilai curah hujan terendah $1 \mathrm{~mm} / \mathrm{jam}$ dan tertinggi $8,5 \mathrm{~mm} / \mathrm{jam}$.Pada bulan Agustus nilai hujan terendah $0,03 \mathrm{~mm} / \mathrm{jam}$ dan tertinggi 5,7 $\mathrm{mm} / \mathrm{jam}$.

Berdasarkan tabel curah hujan, dapat diketahui bahwa distribusi nilai curah hujan pada bulan Nopember-Desember menunjukkan nilai yang lebih besar yang berarti pada bulan tersebut termasuk dalam kategori bulan basah. Sedangkan pada bulan Juli-Agustus menunjukkan nilai curah hujan yang lebih kecil yang berarti pada bulan - bulan termasuk dalam bulan kering.

\section{Analisa Perbandingan Curah Hujan Dari NOAA-19 AHRR Dengan Data Curah Hujan Lapangan.}

Pengolahan curah hujan menggunakan citra NOAA-AVHRR dan curah hujan lapangan memberikan hasil nilai yang berbeda.Citra NOAA-AVHRR merupakan data penginderaan jauh hasil dari pengamatan menggunakan media satelit. Sedangkan data lapangan diperoleh dari akumulasi data hasil pengukuran in-situ stasiun penakar hujan dalam satu hari.
Hal inilah yang mempengaruhi hasil pengolahan curah hujan antara citra NOAAAVHRR dengan data curah hujan lapangan. Data curah hujan dari stasiun penakar hujan sebagai hasil pengukuran in-situ dijadikan sebagai acuan dalam perbandingan curah hujan. Perbandingan curah hujan menggunakan data tanggal sama. Dalam penelitian ini, nilai curah hujan dari NOAA $A V H R R$ telah diubah menjadi curah hujan bulanan. Untuk membandingkan citra NOAA $A V H R R$ dengan data curah hujan di lapangan menggunakan metode korelasi.

Korelasi curah hujan rata-rata bulanan pada bulan Juli (bulan kering), memilki model matematis $y=0,451 x+0,668 R^{2}=0,430$ dengan nilai $\mathrm{R}=65 \%$ dan Agustus(bulan kering) memiliki model matematis $y=0,360 x+1,099 R^{2}$ $=0,499$ dengan nilai $R=70 \%$ sedangkan korelasi pada bulan November(bulan basah) memiliki model matematis $y=0,17 x+2,774 R^{2}$ $=0,464$ dengan nilai $\mathrm{R}=68 \%$ dan Desember(bulan basah) memiliki model matematis $y=0,248 x+3,163 R^{2}=0,440$ dengan nilai $R=66 \%$. Hasil perhitungan korelasi dengan menggunakan rumus umum maupun melalui menunjukkan nilai $r x y^{2}=R^{2}$ Berdasarkan interpretasi koefisien korelasi oleh Guilford,dapat dikatakan bahwa nilai korelasi yang didapatkan di atas termasuk dalam korelasi sedang.

\section{PENUTUP}

1.Perbedaan curah hujan antara citra NOAA$A V H R R$ dengan stasiun penakar hujan terjadi karena curah hujan yang terekam oleh citra NOAA-AVHRR adalah kumpulan titik-titik air dan kristal-kristal air yang membentuk awan, sedangkan curah hujan dari stasiun penakar hujan adalah titik-titik air dari awan yang telah sampai di bumi.

2. Hasil penelitian diperoleh intensitas curah hujan estimasi minimal $1,806 \mathrm{~mm} / \mathrm{jam}$ dan maksimal 9,304 $\mathrm{mm} / \mathrm{jam}$ pada bulan Nopember-Desember (bulan basah) dan minimal 0,0 mm/jam dan maksimal 5,047 $\mathrm{mm} / \mathrm{jam}$ pada bulan Juli-Agustus (bulan kering). 
3. Korelasi curah hujan rata-rata bulanan pada bulan Juli (bulan kering), memilki model matematis $y=0,451 x+0,668 R^{2}=0,430$ dengan nilai $\mathrm{R}=65 \%$ dan Agustus(bulan kering) memiliki model matematis $\mathrm{y}=$ $0,360 x+1,099 R^{2}=0,499$ dengan nilai $R=70 \%$ sedangkan korelasi pada bulan November(bulan basah) memiliki model matematis $y=0,17 x+2,774 R^{2}=0,464$ dengan nilai $R=68 \%$ dan Desember(bulan basah) memiliki model matematis $y=0,248 x$ $+3,163 R^{2}=0,440$ dengan nilai $R=66 \%$. Dapat dikatakan bahwa nilai korelasi yang didapatkan di atas termasuk dalam korelasi sedang (Guilford, J.P. 1956)

4.Berdasarkan analisa peta curah hujan bulan November-Desember(bulan basah) menunjukkan bahwa sebagian besar Pulau Jawa memiliki nilai curah hujan yang termasuk dalam klasifikasi intensitas curah hujan lebat sedangkan pada bulan JuliAgustus(bulan kering) menunjukkan bahwa sebagian besar Pulau Jawa memiliki nilai curah hujan yang termasuk dalam klasifikasi intensitas curah hujan ringan.

\section{DAFTAR PUSTAKA}

Balitklimat. 2007. Penggunaan Metode Filter Kalman Untuk Prakiraan Curah Hujan Di Sentra Produksi Pangan. Balai Penelitian Agroklimat Dan Hidrologi. Badan Litbang Pertanian.

Prasasti, I, dkk. 2000. Model Ekstraksi Data NOAATOVS/ NOAA-KLM-ATOS. Laporan Akhir Riset Unggulan Kemandirian Kedirgantaraan. LAPAN-PSDAL.

Aljabaro, R. 2007. Estimasi Curah Hujan Menggunakan Data Satelit Geostasioner. Tugas Akhir . Bandung : Institut Teknologi Bandung.

Parwati. 2009. Pengolahan Lanjut Data NOAATemperature Brightness (TB). LAPANPSDAL.

Bendix,J.1997.Adjustment Of The Convective Strati form Technique (CST) To Estimate 1991/93 El Nino Rainfall Distribution In Ecuador And Peru By Means of Meteosat-3 Ir Data. Int. J. Remote Sensing, Vol. 18, No. 6. Department of Geography, University of Bonn, Jerman.

Purwadhi, S.H. 2001. Interpretasi Citra Digital.Grasindo. Jakarta.
Guilford, J.P. 1956. Fundamental Statistics in Psychology and Education. (p. 145). New York: McGraw Hill.

LAMPIRAN
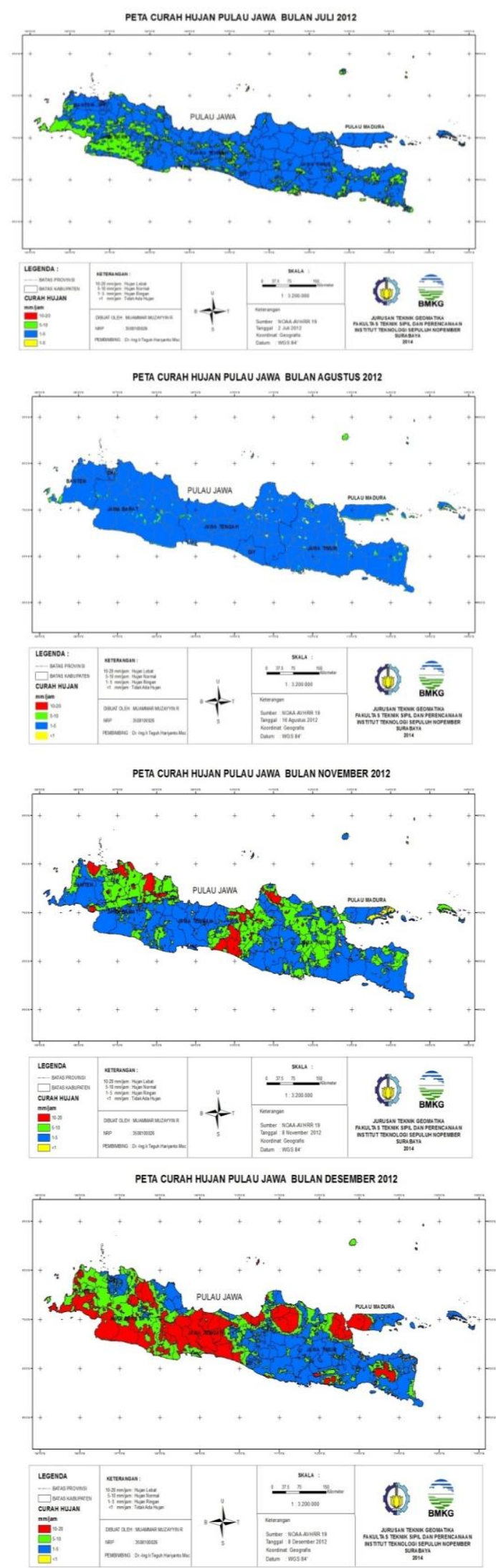